\title{
Anticancer Effect of Cisplatin-Loaded Poly (Butylcyanoacrylate) Nanoparticles on A172 Brain Cancer Cells Line
}

\author{
Mohsen Chiani ${ }^{1}$, Attabak Toofani Milani ${ }^{2}$, Mahdieh Nemati ${ }^{3}$, Jalal Rezaeidian ${ }^{4}$, \\ Hossein Ehsanbakhsh ${ }^{5}$, Zohre Ahmadi ${ }^{6}$, Ebrahim Mazloomi ${ }^{7 *}$, Vahideh Sadeghi ${ }^{8}$, \\ Azim Akbarzadeh Khiyavi ${ }^{\text {* }}$
}

\begin{abstract}
Background: Drug delivery systems have been designed to achieve targeted delivery and control the release rate of the drugs. A serious challenge associated with drug delivery systems is the presence of the blood-brain barrier which limits drugs penetration. In the current study, the effects of cisplatin nanoparticles on A172 brain cancer cell line were investigated. Methods: Cisplatin nanoparticles were produced by miniemulsion polymerization technique and their properties were evaluated. Drug release assay was performed to characterize the nanoparticles' properties. Here, we examined the effects of cisplatin nanoparticles and free form of cisplatin on A172 cancer cell line. MTT assay was performed for different concentrations of the drug. To measure the apoptosis rate in A172 cell line in the presence of cisplatin nanoparticles or its free from, Annexin V staining method was used. Results: Our results indicated that loading type of cisplatin was physical loading and only $4.7 \%$ of cisplatin was released after 68 h. Furthermore, MTT assay showed that cisplatin nanoparticles in all concentrations had more cytotoxic effects on the cells comparing with the free form of cisplatin and control groups. We also showed that cisplatin nanoparticles could increase apoptosis in cancer cells more than the drug in the free form by using flow cytometry technique. Conclusion: Overall, these findings proved that cisplatin loaded on poly (Butylcyanoacrylate) nanoparticles, was more efficient than the free form of cisplatin in treating A172 cancer cell line.
\end{abstract}

Keywords: Cisplatin- poly (Butylcyanoacrylate) nanoparticles- apoptosis- A172 cells

Asian Pac J Cancer Prev, 20 (1), 303-309

\section{Introduction}

A specialized vascular endothelium covers the brain, which is called blood-brain barrier (BBB). The BBB has direct interactions with neurons, pericytes, and alsoastrocytes. Furthermore, it separates and protects the brain from circulating blood (Daneman and Prat, 2015). Some functions have been described for the BBB such as ion regulation, separating central and peripheral transmitter pools, and selective penetration of macromolecules and nutrients (Abbott et al., 2010). Although the presence and integrity of the BBB is vital for normal brain functions, it prevents efficient drug delivery to the brain as well. Some solutions have been proposed to overcome such problem, including manipulating the chemical structure of the drugs and attaching the drugs to liposomes, immunoglobulins, and nanoparticles (Tajes et al., 2014). In many cases, local drug delivery is preferred over systemic drug delivery with a slow release rate in order to decrease side effects and toxicity induced by the drug. Drug delivery systems are engineered biomedical tools that are used to control the release rate or targeted delivery of the drugs. However, some introduced systems are able to control both features (Jain, 2008; Tiwari et al., 2012). Indeed, nanoparticles have numerous medicinal and industrial usages (Ebrahimi Far et al., 2017; Izadi et al., 2016). Definitely, different nanoparticles (NPs) are used in drug delivery such as liposomal NPs (Izadi et al., 2016; Poy et al., 2016; Poy et al., 2018), niosomal nanoparticles (Amiri et al., 2016; Kanaani et al., 2017), and Nano-Poly Butyl Cyanoacrylate (Kanaani et al., 2017). Nanotechnology proposed new treatment methods for human diseases such as cancers. Research has shown that NPs can pass the BBB and can be used as an effective drug delivery system in some diseases 
such as brain cancer (Kreuter et al., 2002; Costantino et al., 2005; Sumner and Kopelman, 2005). Various types of NPs with natural (i.e. Chitosan and Liposomes) or synthetic (i.e. Polyethyleneimine and Polylactic acid) origins have been produced and examined for drug delivery (De Jong and Borm, 2008). Poly (Butylcyanoacrylate) NPs (PBCA-NPs) were the first polymer-based NPs used to deliver the drugs to the central nervous system (Patel et al., 2012).

The effects and properties of these NPs have been studied extensively and research has indicated that it can be used as an efficient delivery system to overcome the barrier in the brain. PBCA NPs have some favorable properties comparing with other NPs such as having small size, easy penetration to capillaries, its stability in in-vitro conditions, and its good ability to pass the BBB and deliver the drugs to the brain cells effectively (Garcia-Garcia et al., 2005; Lin et al., 2012; Masserini, 2013).

Apoptosis is a programmed suicide process that leads to cell death. Although it occurs normally in the body, sometimes it also acts as a defense mechanism. Various triggers have been identified that are able to initiate apoptosis. A good example of such triggers is DNA damage. Some drugs that are used for cancer treatment can cause damage to DNA in some cells and therefore trigger the apoptosis. An instance of such drugs is cisplatin. Cisplatin or cis-diamminedichloroplatinum (II) is a metallic anti-cancer drug that has been used successfully in the treatment of various human cancers (Elmore, 2007; Dasari and Tchounwou, 2014). The drug can cause DNA damage in the cancer cells and subsequently initiate apoptosis (Reedijk and Lohman, 1985). Several delivery systems have been used to carry cisplatin into the target organs, but there is no effective form of the carriers for therapeutic purposes because of the drug's low hydrophilic and lipophilic properties (Bandak et al., 1999; Newman et al., 1999; Vaage et al., 1999; Hirai et al., 2010). In the current study, we investigated the effects of cisplatin-PBCANPs (produced by miniemulsion polymerization method) on A172 cells as a cancer tissuederived cell line.

\section{Materials and Methods}

\section{Materials}

Cisplatin (Cispt), Dimethyl sulfoxide (DMSO), hydrogen chloride, and sodium hydroxide were obtained from the Zhechem (China). The monomer of butylcyanoacrylate (BCA) was purchased from Evobond ${ }^{\circledR}$ Tong Shen Enterprise (Taiwan). FBS and dextran were got from Gibco (USA) and the Zhejiang Chemicals Import and Export Corporation (China), respectively. PEG400 was purchased from KimiagaranEmrooz Chemical (Iran). All other materials were from analytical grade. The A172 cell line was purchased from the cell bank of the Pasteur Institute (Iran). All the experiments were conducted in accordance with the protocols approved by the ethical committee of Pasteur Institute, Tehran, Iran.

NPs Preparation

Preparation of NPs was carried out by miniemulsion polymerization method. For this purpose, $185 \mu \mathrm{l}$ of BCA monomers was added to a mixture containing $100 \mu \mathrm{l}$ of $\mathrm{HCl}(0.01 \mathrm{~N}), 100 \mathrm{mg}$ of honey (Sabalan Co., Iran), $55 \mu \mathrm{l}$ of olive oil (FarzanRahbar Saba Co., Iran), and $120 \mu \mathrm{l}$ of PEG 400. In the next step, $165 \mathrm{mg}$ of dextran and $55 \mathrm{mg}$ of Cispt were added to the formulation and it was mixed again. Then, $18 \mathrm{ml}$ of distilled water was added to the mixture. The mixture was stirred (400 rpm, $10 \mathrm{~min}$ ) to obtain a pre-emulsion solution. Finally, sonication was performed by probe sonicator for $5 \mathrm{~min}(50$. W, Bandel in Sonopuls HD 2070, Bandelin Elec., Germany) and then it was stirred (400 rpm, 3.5h) to complete the polymerization process. Subsequently, $\mathrm{pH}$ of the mixture was neutralized with $\mathrm{NaOH}$ (Kanaani et al., 2017).

\section{Characterization of NPs}

PS (mean size), PDI (size distribution) and $\zeta$-P (zeta potential) of Cispt-PBCA NPs were determined by Zetasizer at $633 \mathrm{~nm}$ (Nano-Zs Zen 3600, Malvern Instruments, UK). Amount of the drug in supernatant was determined by ICP-EOS (Inductively Coupled Plasma Optical Emission Spectrometry) elemental analysis (730-OES, Varian) (Brannon-Peppas and Blanchette, 2004). For this purpose, an emulsion of Cispt-NC was centrifuged for $45 \mathrm{~min}\left(21000 \mathrm{rpm}, 4{ }^{\circ} \mathrm{C}\right)$ and then encapsulation efficiency (E.E) and drug loading efficiency (D.L.E) were calculated using bellow formulas:

\section{Formula 1}

$$
\mathrm{E} . \mathrm{E}(\%)=\frac{\begin{array}{l}
\text { Initial concentration Cispt }(\mathrm{mg} / \mathrm{ml})-\text { Concentration of Cispt in in supernatant } \\
(\mathrm{mg} / \mathrm{ml})
\end{array}}{\text { Amount of Cispt fed initially }(\mathrm{mg} / \mathrm{ml})} \times 100
$$

\section{Formula 2}

$$
\text { D. L. E }(\%)=\frac{\text { Amount of Cispt entrapped in NPs }(\mathrm{mg})}{\text { Amount of NPS }(\mathrm{mg})} \times 100
$$

\section{In-Vitro Drug Release Studies}

To analyze the drug release rate into the serum, Cispt-PBCA NPs suspension was centrifuged and 80 $\mathrm{mg}$ of the pellet was re-dispersed in $8 \mathrm{ml}$ of fresh human serum. Then, it was incubated at $37^{\circ} \mathrm{C}$ while shaking $(150$ cycles/min) using a shaker incubator (kuhner, Birsfelden, Switzerland). In predestinated periods, the tube was centrifuged $\left(21,000 \mathrm{rpm}, 45 \mathrm{~min}, 4^{\circ} \mathrm{C}\right)$ and the supernatant was removed. The pellet was re-dispersed in $8 \mathrm{ml}$ of fresh human serum to measure continuous release rate. The rate of drug release into the supernatant was evaluated using ICP-EOS elemental analysis (Bagherpour Doun et al., 2014).

\section{Cell Viability Studies}

MTT (3-(4,5-dimethylthiazol-2-yl)-2, 5-diphenyl tetrazolium bromide) assay was applied (Brannon-Peppas and Blanchette, 2004) to determine the cytotoxicity effects of Cispton A172 cells line. Cells ( $1 \times 104 /$ well) were cultured in RPMI-1640 medium containing \%10 FBS, penicillin/streptomycin antibiotics $(0.1$ and $0.06 \mathrm{mg} / \mathrm{ml}$ respectively) and incubated at $37 \circ \mathrm{C}$ in 5 percent carbon dioxide (CO2). Twenty-four hours later, the adhered cells to the plate were detached and Cispt-PBCA-NPs and 
F-Cispt (Free cisplatin) at the concentration of $0,2.5,5$, $10,20,30,40,60,80$, and $90 \mu \mathrm{M}$ were prepared and then added into the wells. After 48 hours, $20 \mu$ of MTT solution $(0.5 \mathrm{mg} / \mathrm{ml}$, Sigma-Aldrich, USA) was added to each well. Formazan crystals were dissolved by isopropanol and the absorbance was read at $570 \mathrm{~nm}$ wavelengths using an ELISA reader device (Synergy Multi-Mode Elisa Reader, Bio-Tek, USA). Finally, IC50 was calculated by statistical package Pharm-PCS software (Springer Verlag, USA). Cell Viability was calculated using following formula:

Cell Viability $=[$ mean OD of treated cells - (mean OD of blank)] / [mean OD of control - (mean OD of blank)] $\times 100$

In vitro, data were analyzed by SPSS (version 13.0). Data were expressed as the Mean \pm SD $(n=3)$ and unpaired-samples t-test was used as statistical tests. The significance level was set at $\mathrm{p}<0.05$.

\section{Flow cytometry analysis}

To study and quantify apoptosis in A172 cells induced by the Cispt-PBCA-NC, the cells were stained with FITC Annexin V kit (BioLegend Inc., San Diego, USA) according to manufacturer's instruction. Briefly, $5 \times 10^{5}$ of A172 cells were seeded in each well of the six-well plate and allowed to attach and grow for $24 \mathrm{~h}$ at $37^{\circ} \mathrm{C}$ in $5 \% \mathrm{CO}_{2}$. After that, the medium was replaced with fresh medium containing $3.5 \mu \mathrm{M}$ of Cispt-PBCA-NC and F-Cispt as triplicates. Forty-eight hours later, the cells were collected by centrifugation and the supernatant was discarded. The cells were washed two times by cold BioLegend cell staining buffer and then suspended in Annexin-V binding buffer. The concentration of re-suspended cells in binding buffer was $1 \times 10^{6}$ cells $/ \mathrm{mL}$. Then, $100 \mu \mathrm{L}$ of

the cell suspension was transferred to the test tubes and $5 \mu \mathrm{L}$ of FITC Annexin V and $10 \mu \mathrm{L}$ of PI solution were added to the tubes. The tubes were incubated in a dark place for $15 \mathrm{~min}$ and at room temperature. Afterward, $400 \mu \mathrm{L}$ of Annexin-V binding buffer was added to each tube and then the suspension was analyzed using a flow cytometry device (Shellman et al., 2005).

\section{Results}

\section{Characterization of NPS}

As illustrated in Figure 1, our results showed that the preparation of the NPs according to our protocol produced particles with average size of $451.2 \pm 11.1 \mathrm{~nm}$. Furthermore, zeta potential and size distribution of the NPs were $0.452 \pm 0.09$ and $-19.5 \pm 2.8 \mathrm{mV}$, respectively. The E.E and D.L.E percentages were 30 and 6, respectively. In other words, $30 \%$ of the drug was carried with NPs and Cispt accounted for $6 \%$ of NPs' weight.

\section{The Release rate of cisplatin}

As shown in Figure 2, 4.7\% (W/W) of Cispt was released after $68 \mathrm{~h}$. Although an intense release of the encapsulated drug (44\%) was considered during the first $5 \mathrm{~h}$, it was reduced over the time.

Table 1. $\mathrm{IC}_{50}$ Values Comparison between F-Cispt and Ciapt-PBCA-NPs in the Cell Line A172. IC50 value is almost 2-fold greater in F-Cispt compared to CisptPBCA-NPs.

\begin{tabular}{lccc}
\hline Brain Cell Line & Cispt-PBCA NPs $(\mu \mathrm{M})$ & F-Cispt $(\mu \mathrm{M})$ & P Value \\
\hline A172 & $25.4 \pm 3.1$ & $49.9 \pm 5.9$ & $\mathrm{P}<0.01$ \\
\hline Data are presented as mean \pm SD $(\mathrm{n}=3)$ & &
\end{tabular}

Table 2. Effects of Cispt-PBCA-NPs, F-Cispt on Apoptosis in A172 Cell Line. Results indicated that Cisplatin NPs could increase early and late apoptotic cells number and also necrotic cells comparing to free cisplatin.

\begin{tabular}{|c|c|c|c|c|}
\hline Formulation & Viable Cells \% An-/PI- & Early Apoptosis \% An+/PI- & Late Apoptosis $\%$ An+/PI+ & Necrotic Cells \% An-/PI+- \\
\hline Cispt-PBCA NPs & $81.8 \pm 9.9$ & $12.2 \pm 1.5$ & $3.64 \pm 0.9$ & $0.54 \pm 0.09$ \\
\hline F-Cispt & $88.7 \pm 9.4$ & $8.11 \pm 1.9$ & $2.01 \pm 0.7$ & $0.32 \pm 0.07$ \\
\hline Control & $96.7 \pm 2.1$ & $0.81 \pm 0.4$ & $0.83 \pm 0.05$ & $0.3 \pm 0.08$ \\
\hline
\end{tabular}

Data are presented as mean $\pm \mathrm{SD}(\mathrm{n}=3)$

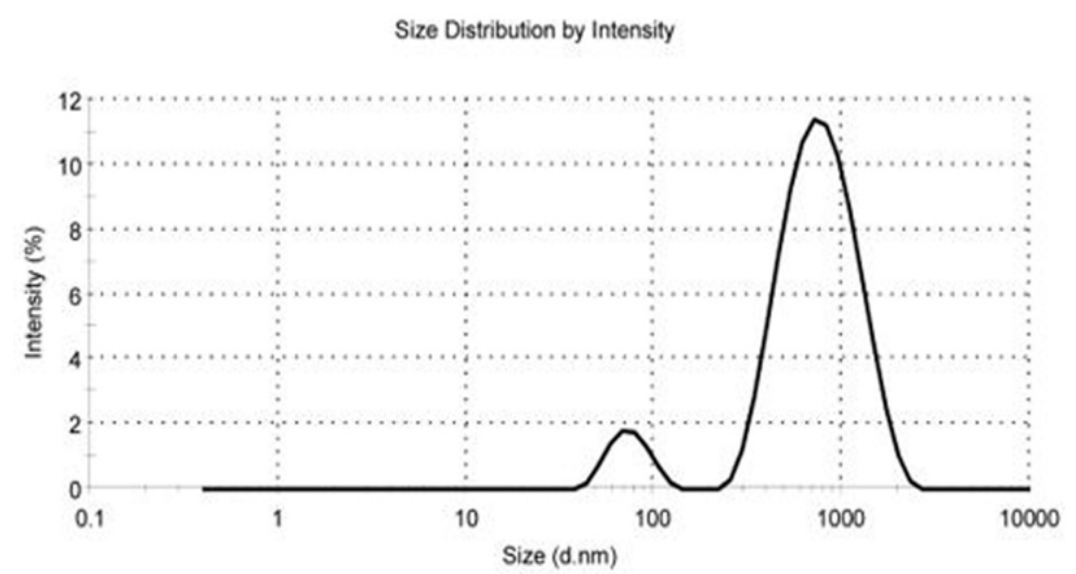

Figure 1.The Micrograph of Size and Size Distribution of Cisplatin Loaded PBCA Nanoparticles Obtained from Zetasizer Instrument. 


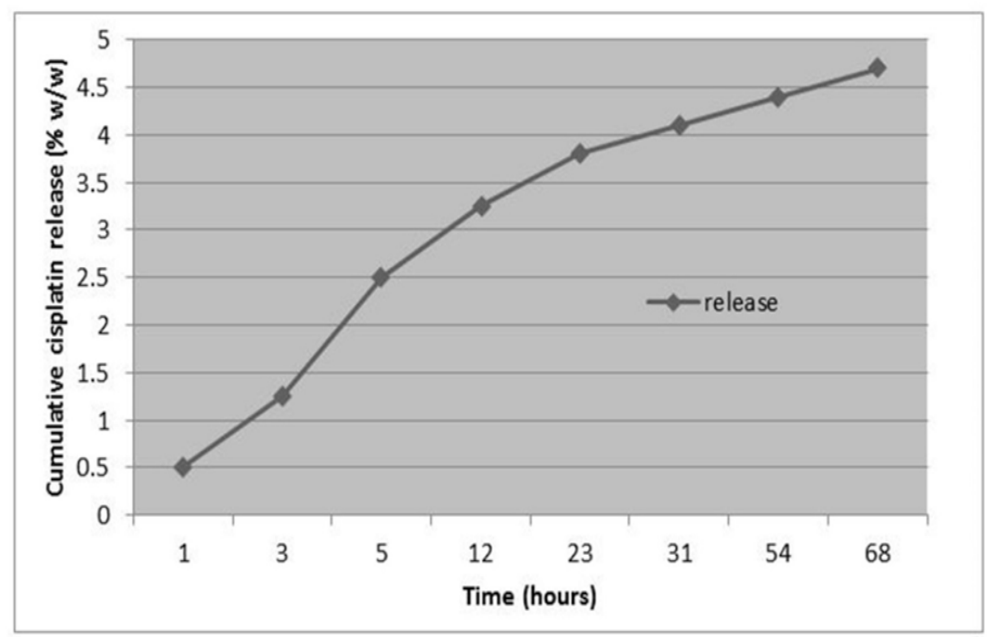

Figure 2. Cisplatin Release Pattern during the Time. PBCA-NPs successfully produced by miniemulsion technique. Cispt was successfully encapsulated in the developed particles with sustained release behavior in a period of 68 hours. Results were expressed as mean $\pm \mathrm{SD}$ values.

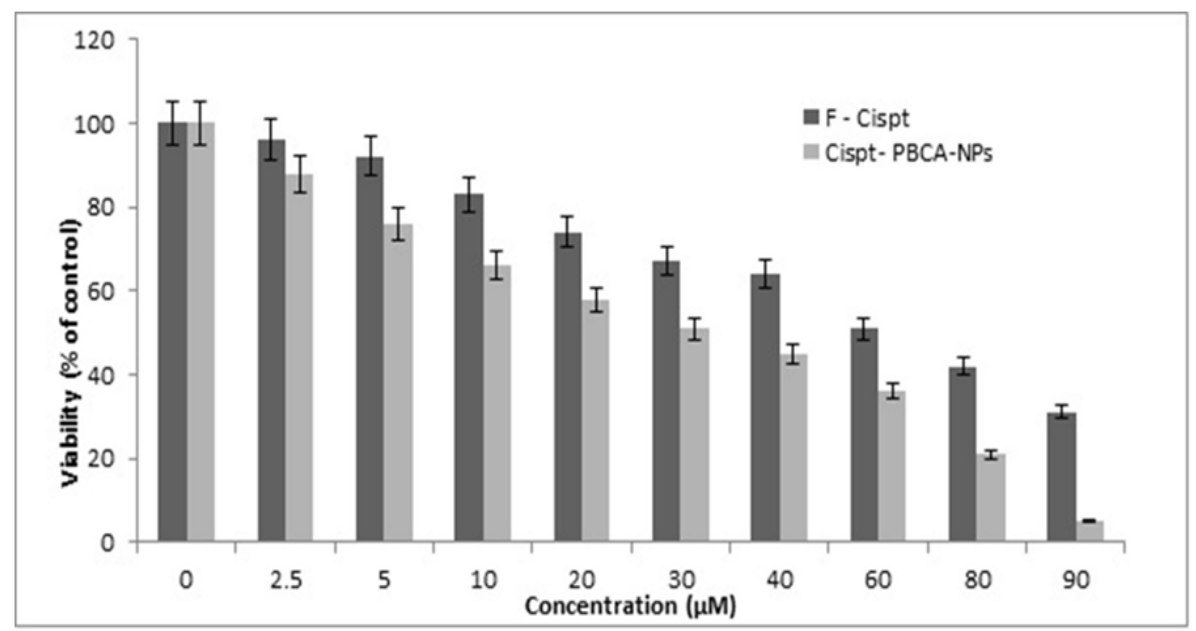

Figure 3. Cytotoxic Effects of Cispt-PBCA-NPs and F-Cispt on the Viability of Brain Cancer Cell Line A172 (MTT assay). Cisplatin loaded nanoparticles had higher cytotoxic effects on the cell line and in all cases killed more cancer cells. Results were expressed as mean $\pm \mathrm{SD}$ values of three independent experiments.

\section{Cytotoxicity effects of Cispt-PBCA NPS}

According to Figure 3 , the safe concentration of control NPs was $60 \mu \mathrm{g} / \mathrm{ml}$. MTT assay showed that cytotoxicity effects of cisplatin-loaded NPs were dosedependent and mostly observed in concentration of 90 $\mu \mathrm{M}$. Furthermore, in all the concentrations Cispt-PBCA
NPs had higher cytotoxic effects than F-Cispt. Results indicated that the values for Cispt-PBCANPs and F-Cispt were 25.4 \pm 3.1 and 49.9 \pm 5.9 , respectively (Table 1 ).

\section{Detection of apoptosis by flow cytometry}

Our results showed that treatment of the cells with

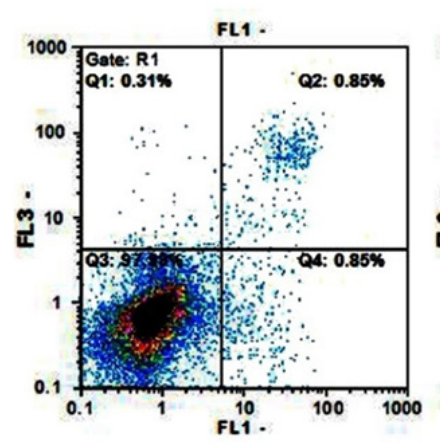

A

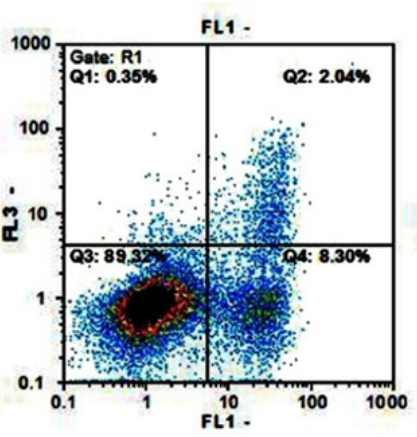

B

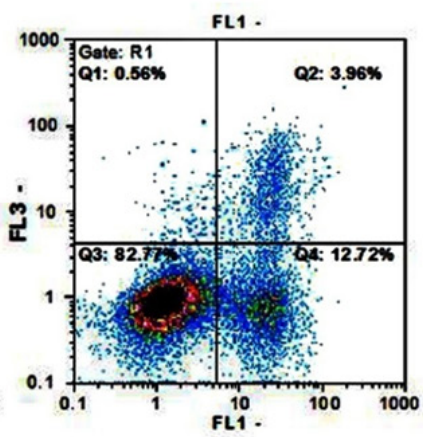

C

Figure 4. Demonstration of the Gating Strategy for Flow Cytometric Analysis. (A) Dot plot of flow cytometry assay for control, (B) F-Cispt (C) and Cispt-PBCA-NPs groups after 48 hours. 
Cispt-PBCA NPs could increase apoptosis rate in comparison with F-Cispt and control groups. Besides, the rate of necrotic cells was also higher in the group treated with the NPs compared to control and F-Cispt groups (Table 2).

\section{Discussion}

Considering all types of chronic disorders, including diabetes, metabolic syndrome, etc. (Goodarzi et al., 2014; Ebrahimi Far et al., 2015; Mohammadian et al., 2015; (cancer is the most important) Ebrahimi Far et al., 2017 (In the recent surveys, the effect of numerous chemotherapeutic drugs on various cancer cell lines have been evaluated (Sajjadiyan et al., 2016; Mohamadi et al., 2017; Mohammadian et al., 2017; Zeynali M et al.,2018). Moreover, herbal based therapeutic agents have also been studied in cancer therapy (Rostaminasab et al., 2015; Arshad et al., 2018). Considering brain cancers and tumors, the most aggressive brain tumor form in human is Glioblastoma and its mortality rate is pretty high (Cheo et al., 2017).

The presence of $\mathrm{BBB}$ is a challenging problem in the treatment of such diseases. In fact, the drugs can't pass through the barrier efficiently, resulting in inadequate amount of drug delivery to the target cells. Chemotherapy has been applied to treat human cancers and tumors over the decades. However, this method has some undesirable consequences such as systemic toxicity and low bioavailability. NPs are extremely useful to treat cancers and tumors in the human being. Due to lower systemic toxicity, NPs have higher efficiency in the treatment of cancer in comparison with free form of the drugs. They also can overcome some problems of traditional chemotherapy by passing through BBB and delivering sufficient amounts of the drugs to the brain cells. However, some NPs loaded with cisplatin showed undesirable results (Hirai et al., 2010; Zamboni et al., 2012). In the current study, we successfully produced PBCA-NPs which were loaded with the high level of cisplatin. Therefore, our results confirmed that miniemulsion polymerization is an applicable method to produce cispt-PBCA NPs. On the other hand, we utilized two natural products; honey and olive oil during the preparation of NPs. These two natural products have brilliant properties and negligible toxicity and previous research has shown that using honey and olive oil in NPs' formulation can affect NPs' properties in a positive manner (Sreelakshmi et al., 2011; Palanisamy KL, 2013; Wu et al., 2013). Polymerization process occurred after adding water and in this step, the medium was almost colorless and after sonication and completing the process the color changed to milky (Kanaani et al., 2017). In this study, the percentages of E.E and D.L.E were 30 and 6 , respectively. In other words, $30 \%$ of the drug was carried with NPs and Cispt, accounting for $6 \%$ of NPs' weight.

The cumulative release rate of Cispt from the Cispt-PBCA-NPs into the fresh human serum was measured during $68 \mathrm{~h}$ (Figure 2). High encapsulation efficiency indicated that only $4.7 \%(\mathrm{~W} / \mathrm{W})$ of Cispt was released after $68 \mathrm{~h}$. However, in the first five hours of evaluation, a burst release ( $44 \%$ of encapsulated drug) of Cispt was observed, probably reflecting the release of adsorbed Cispt on the surface of PBCA-NPs. Release rate decreased over time following about $31 \mathrm{~h}$ and only $0.30 \%$ of Cispt was released. The low-level release rate may be attributed to the presence of polyethylene glycol (PEG). Furthermore, it can improve the stability and increase the chance of drug delivery to the tumor cell (Otsuka et al., 2003).

Our results indicated that the safe concentration of control NPs was $60 \mu \mathrm{g} / \mathrm{ml}$. However, other studies have shown higher safe concentrations for the NPs. According to our findings, cell viability was decreased in a dose-dependent manner after exposure of the brain cell line to Cispt-PBCA-NPs and F-Cispt according to MTT test. In a comparison between two treated cases, higher cytotoxic effects were obtained in all Cispt-PBCA-NPs concentrations than F-Cispt (Figure 3). The experimental data for IC50 values showed that cytotoxicity effects increased in a dose-dependent manner and the highest cytotoxic effect was observed in concentration of $90 \mu \mathrm{M}$. The results obviously showed better cytotoxic effects of the NPs in killing A172 brain cancer cells line comparing with those of the free drug, that is in line with a previous study in this regard (Bendale et al., 2017).

To illuminate the effect of Cispt-PBCA-NPs on apoptosis in A172 cells, we used Annexin V-FITC/PI dyes and analyzed the samples by flow cytometry device (Bendale et al., 2017). Using this staining method determines the cell viability in the different modes; namely, viable cells, early apoptosis cells, late apoptosis cells, and necrotic cells. Our results indicated that a higher concentration of Cispt-PBCA-NPs increased apoptotic cells numbers. Similarly, a previous research showed that cisplatin NPs could increase early and late apoptotic cells as well as necrotic cell numbers in A172 cell line (Bendale et al., 2017). Our results are also in line with those researchers and showed that Cispt-PBCA-NPs could increase apoptotic and necrotic cells number not only comparing with the control group but also in comparison with free cisplatin.

In conclusion, in the current study, we showed that production of cisplt-PBCA-NPs with our protocol could be an effective formulation to treat A172 brain cancer cell line. The drug has been loaded on NPs physically and the particles had a fine low release rate and also contained a high level of the drug. In addition, our results showed that cisplatin loaded on PBCA-NPs were more efficient than the free drug. Cisplt-PBCA NPs could release the drug gradually and could kill more cancer cells in all concentrations compared to the free drug. Furthermore, we showed that Cisplt-PBCA NPs could induce early and late apoptosis more than the free form of cisplatin. All in all, such data suggested that cisplatin loaded on our PBCA-NPs formulation could be more useful and efficient in the treatment of A172 brain cancer cell line compared to cisplatin in free form.

\section{Conflict of Interests}

None to declare. 


\section{Acknowledgments}

The authors would like to thank the Department of Biotechnology, Government of Iran, for providing financial support to conduct the current research.

\section{References}

Abbott NJ, Patabendige AA, Dolman DE, et al (2010). Structure and function of the blood-brain barrier. Neurobiol Dis, 37, 13-25.

Amiri B, Ebrahimi Far M, Saffari Z, et al (2016). Preparation, characterization and cytotoxicity of silibinin containing nanoniosomes in T47D human breast carcinoma cells. Asian Pac J Cancer Prev, 17, 3833-6.

Arshad Z, Rezapour-Firouzi S, Mohammadian M, et al (2018). The sources of essential fatty acids for allergic and cancer patients; a connection with insight into mammalian target of rapamycin: A narrative review. Asian Pac J Cancer Prev, 19, 2391-2401.

Bagherpour Doun SK, Alavi SE, Koohi Moftakhari Esfahani M, et al (2014). Efficacy of Cisplatin-loaded poly butyl cyanoacrylate nanoparticles on the ovarian cancer: an in vitro study. Tumour Biol, 35, 7491-7.

Bandak S, Goren D, Horowitz A, et al (1999). Pharmacological studies of cisplatin encapsulated in long-circulating liposomes in mouse tumor models. Anticancer Drugs, 10, 911-20.

Bendale Y, Bendale V, Paul S (2017). Evaluation of cytotoxic activity of platinum nanoparticles against normal and cancer cells and its anticancer potential through induction of apoptosis. Integr Med Res, 6, 141-8.

Brannon-Peppas L, Blanchette JO (2004). Nanoparticle and targeted systems for cancer therapy. Adv Drug Deliv Rev, 56, 1649-59.

Cheo ST, Lim GH, Lim KH (2017). Glioblastoma multiforme outcomes of 107 patients treated in two Singapore institutions. Singapore Med J, 58, 41-5.

Costantino L, Gandolfi F, Tosi G, et al (2005). Peptide-derivatized biodegradable nanoparticles able to cross the blood-brain barrier. J Control Release, 108, 84-96.

Daneman R, Prat A (2015). The blood-brain barrier. Cold Spring Harb Perspect Biol, 7, a020412.

Dasari S, Tchounwou PB (2014). Cisplatin in cancer therapy: molecular mechanisms of action. Eur J Pharmacol, 740, 364-78.

De Jong WH, Borm PJ (2008). Drug delivery and nanoparticles:applications and hazards. Int J Nanomedicine, 3, 133-49.

Elmore S (2007). Apoptosis: a review of programmed cell death. Toxicol Pathol, 35, 495-516.

Garcia-Garcia E, Andrieux K, Gil S, et al (2005). Colloidal carriers and blood-brain barrier (BBB) translocation: a way to deliver drugs to the brain?. Int J Pharm, 298, 274-92.

Ebrahimi Far M, Hasanzade Ganroudsari M, Kazemi M, et al (2017). Enhancing effects of curcumin on cytotoxicity of paclitaxel, methotrexate and vincristine in gastric cancer cells.Asian Pac J Cancer Prev, 18, 65-8.

Ebrahimi Far M, Mazdapour M, Kaki A, et al (2015). Comparison of biochemical factors and liver enzymes in type 2 diabetes patients and healthy individuals. Bull Env Pharmacol Life Sci, 4, 1-4.

Ebrahimi Far M, Nili-Ahmadabadi A, Akbarzadeh A, et al (2017). Preparation, characterization and cytotoxic effects of pegylated nanoliposomal containing carboplatin on ovarian cancer cell lines. Ind J Clin Biochem, 32, 230-4.

Goodarzi MT, Mohammadian M, Borzouei Sh, et al (2014).
Association between plasma cholesteryl ester transfer protein activity and lipid profiles in metabolic syndrome in an Iranian population. Int Res J Biological Sci, 3, 89-90.

Hirai M, Minematsu H, Hiramatsu Y, et al (2010). Novel and simple loading procedure of cisplatin into liposomes and targeting tumor endothelial cells. Int J Pharm, 391, 274-83.

Izadi M, Ebrahimi Shahemabadi H, Kanaani L, et al (2016). Investigation of characteristics of loaded carboplatin on the liposomal nanoparticles on the cell carcinoma of the human brain c6. Adv Biores, 7, 113-8.

Izadi M, Ebrahimi Far M, Kanaani L, et al (2016). Remove nickel (II) from drinking water using thiol-functionalized chitosan. Adv Biomedical Res, 7, 107-12.

Jain KK (2008). Drug delivery systems - an overview. Methods Mol Biol, 437, 1-50.

Kanaani L, Ebrahimi Far M, Kazemi SM, et al (2017). General characteristics and cytotoxic effects of nano-poly (butyl cyanoacrylate) containing carboplatin on ovarian cancer cells. Asian Pac J Cancer Prev, 18, 87-91.

Kanaani L, Javadi I, Ebrahimi Far M, et al (2017). Effects of cisplatin-loaded niosomal nanoparticles on BT-20 human breast carcinoma cells. Asian Pac J Cancer Prev, 18, 365-8.

Kreuter J, Shamenkov D, Petrov V, et al (2002). Apolipoprotein-mediated transport of nanoparticle-bound drugs across the blood-brain barrier. J Drug Target, 10, 317-25.

Lin Y, Pan Y, Shi Y, et al (2012). Delivery of large molecules via poly(butyl cyanoacrylate) nanoparticles into the injured rat brain. Nanotechnology, 23, 165101.

Masserini M (2013). Nanoparticles for brain drug delivery. ISRN Biochem, 2013, 238428.

Newman MS, Colbern GT, Working PK, et al (1999). Comparative pharmacokinetics, tissue distribution, and therapeutic effectiveness of cisplatin encapsulated in longcirculating, pegylated liposomes (SPI-077) in tumor-bearing mice. Cancer Chemother Pharmacol, 43, 1-7.

Mohamadi N, Mohammadian M, Toofani Milani A, et al (2017). Toxicity of cisplatin-loaded poly butyl cyanoacrylate nanoparticles in a brain cancer cell line: Anionic polymerization results. Asian Pac J Cancer Prev, 18, 629-32.

Mohammadian M, Zeynali S, Azarbaijani AF, et al (2017). Cytotoxic effects of the newly-developed chemotherapeutic agents 17-AAG in combination with oxaliplatin and capecitabine in colorectal cancer cell lines. Res Pharm Sci, 12, 517-25.

Mohammadian M, Toofani Milani A, HassasM R, et al (2015). Evaluation of serum iron, zinc and their relationships with glycemic control status in Iranian elderly women with type 1 diabetes mellitus. J Pharm Pharmacol, 3, 411-6.

Otsuka H, Nagasaki Y, Kataoka K (2003). PEGylated nanoparticles for biological and pharmaceutical applications. Adv Drug Deliv Rev, 55, 403-19.

Palanisamy KL MSN, Devabharathi V, Thangarasu P (2013). Synthesis and characterization of olive oil mediated iron oxide nanoparticles. Dig J Nanomater Bios, 8, 607-12.

Patel T, Zhou J, Piepmeier JM, et al (2012). Polymeric nanoparticles for drug delivery to the central nervous system. Adv Drug Deliv Rev, 64, 701-5.

Reedijk J, Lohman PH (1985). Cisplatin: synthesis, antitumour activity and mechanism of action. Pharm Weekbl Sci, 7, 173-80.

Poy D, Akbarzadeh A, Ebrahimi Shahmabadi H, et al (2016). Reparation, characterization and cytotoxic effects of liposomal nanoparticles containing cisplatin: An in vitro study. Chem Biol Drug Des, 88, 568-73.

Poy D, Ebrahimi Shahemabadi H, Akbarzadeh A, et al (2018). Carboplatin liposomal nanoparticles: preparation, 
characterization and cytotoxicity effects on lung cancer in vitro environment. Int J Polym Mater Po, 67, 367-70.

Rostaminasab S, Toofani Milani A, Mohammadian M, et al (2015). Antitumor immunostimulatory effect of sitosterol from salvia atropatana on tumor bearing mice. Adv Biores, 6, 133-40.

Sajjadiyan SZ, Toofani Milani A, Mohammadian M, et al (2016). Preparation of silibinin loaded pegylatedniosomal nanoparticles and investigation of its effect on MCF-10A human breast cancer cell line. Der Pharm Lett, 8, 70-5.

Shellman YG, Ribble D, Miller L, et al (2005). Lovastatin-induced apoptosis in human melanoma cell lines. Melanoma Res, $\mathbf{1 5}$, 83-9.

Sreelakshmi C, Datta KK, Yadav JS, et al (2011). Honey derivatized $\mathrm{Au}$ and $\mathrm{Ag}$ nanoparticles and evaluation of its antimicrobial activity. J Nanosci Nanotechnol, 11, 6995-7000.

Sumner JP, Kopelman R (2005). Alexa Fluor 488 as an iron sensing molecule and its application in PEBBLE nanosensors. Analyst, 130, 528-33.

Tajes M, Ramos-Fernandez E, Weng-Jiang X, et al (2014). The blood-brain barrier: structure, function and therapeutic approaches to cross it. Mol Membr Biol, 31, 152-67.

Tiwari G, Tiwari R, Sriwastawa B, et al (2012). Drug delivery systems: An updated review. Int J Pharm Investig, 2, 2-11.

Vaage J, Donovan D, Wipff E, et al (1999). Therapy of a xenografted human colonic carcinoma using cisplatin or doxorubicin encapsulated in long-circulating pegylated stealth liposomes. Int J Cancer, 80, 134-7.

Wu L, Cai X, Nelson K, et al (2013). A green synthesis of carbon nanoparticle from honey for real-time photoacoustic imaging. Nano Res, 6, 312-25.

Yan X, Gemeinhart RA (2005). Cisplatin delivery from poly(acrylic acid-co-methyl methacrylate) microparticles. J Control Release, 106, 198-208.

Zamboni WC, Torchilin V, Patri AK, et al (2012). Best practices in cancer nanotechnology: perspective from $\mathrm{NCI}$ nanotechnology alliance. Clin Cancer Res, 18, 3229-41.

Zeynali MS, Mohammadian M, Kheradmand F, et al (2018). A molecular basis for the synergy between 17 allylamino 17 demethoxy geldanamycin with Capecitabine and Irinotecan in human colorectal cancer cells through VEFG and MMP-9 gene expression. Gene, $\mathbf{6 8 4}, 30-8$.

This work is licensed under a Creative Commons AttributionNon Commercial 4.0 International License. 